\title{
Type II de Quervain's disease: depicting subcompartmentalisation with ultrasound
}

\author{
Ricardo Pereira Dias (1) , João Janeiro (1)
}

Serviço de Imagiologia Geral, Centro Hospitalar Universitário Lisboa Norte EPE, Lisboa, Portugal

\section{Correspondence to} Dr Ricardo Pereira Dias; pereira.dias.ricardo@gmail.com

Accepted 26 May 2021

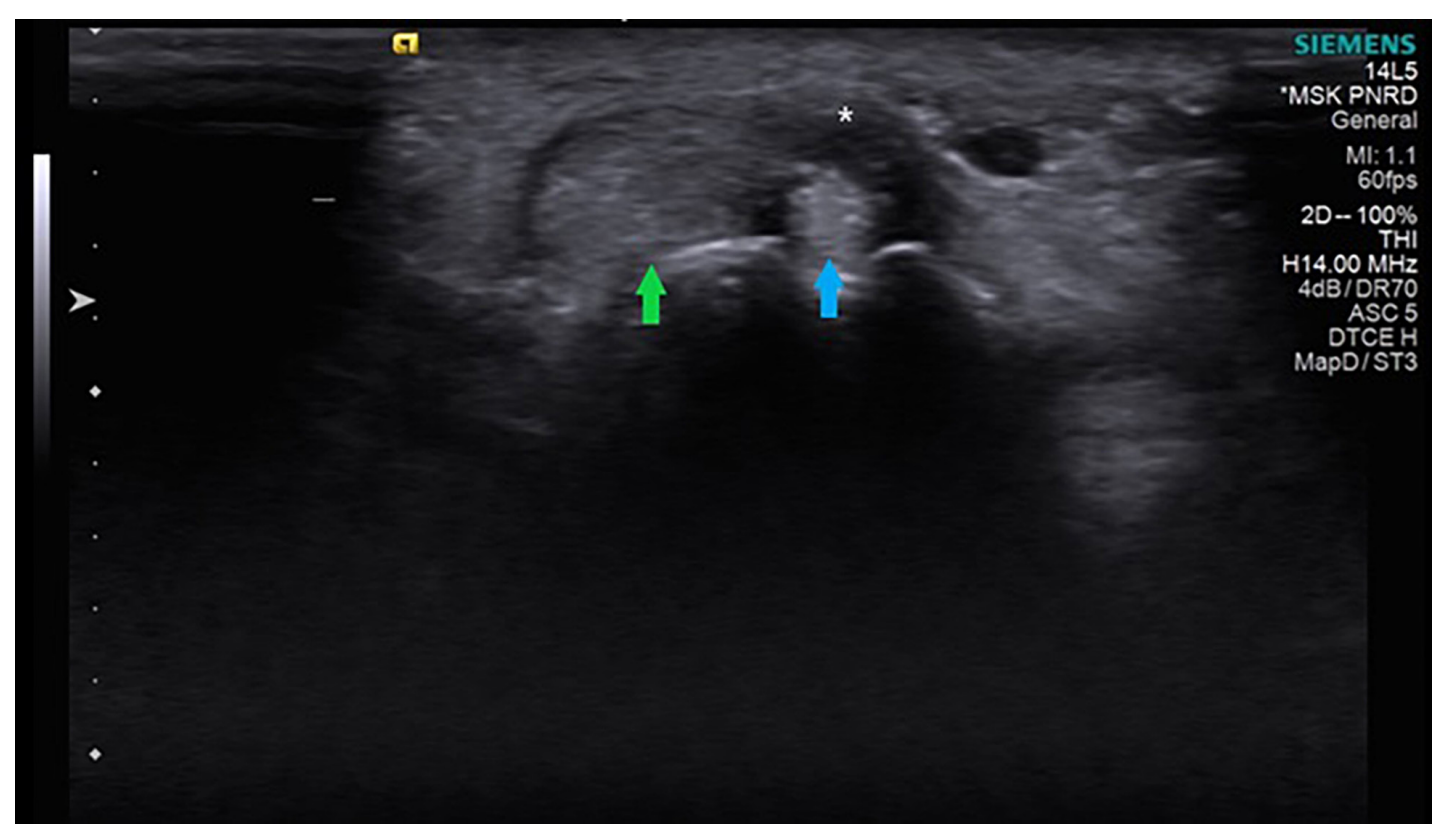

Figure 1 Axial view of the first compartment at the level of the radial styloid process, showing the thickened retinaculum $\left({ }^{*}\right)$ embedding only the extensor pollicis brevis (blue arrow). The abductor pollicis longus (green arrow) is unremarkable.

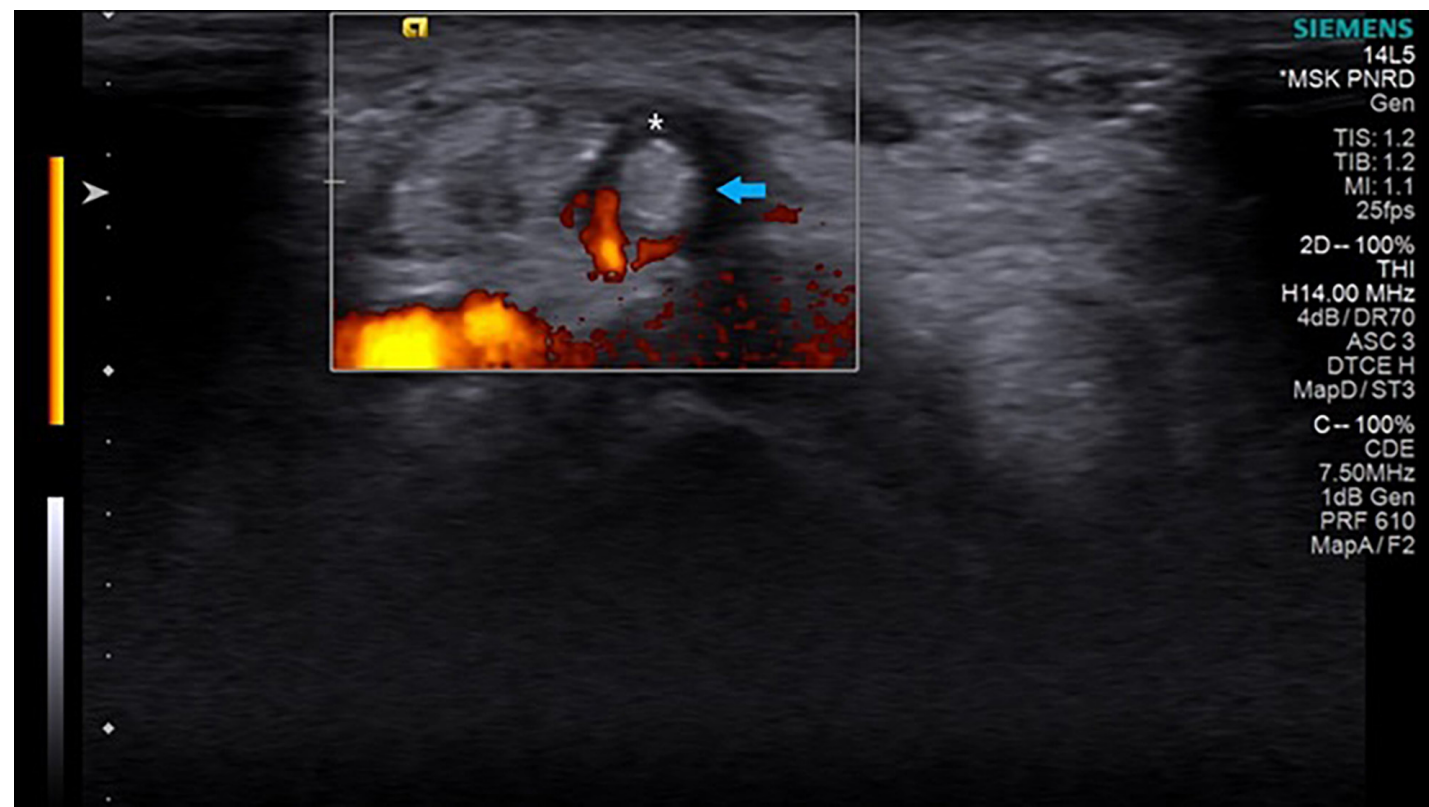

Figure 2 Axial view of the first compartment at the level of the radial styloid process, showing hypervascularity of the thickened retinaculum $\left(^{*}\right)$ embedding only the extensor pollicis brevis (blue arrow).

\section{DESCRIPTION}

A 62-year-old female patient presented with left radial side wrist pain for the past 4 weeks. She denied any history of trauma. On physical examination, she had swelling and tenderness to palpation in the first dorsal compartment with a positive 
Finkelstein's test. On ultrasound, the first extensor compartment revealed complete septation with a thickened retinaculum only embedding the extensor pollicis brevis (EPB) tendon (figure 1) associated with hypervascularity and small tendon sheath effusion (figure 2). The abductor pollicis longus (APL) tendon was unremarkable. The patient was diagnosed with type II de Quervain's disease (DQD) and conservative management was pursued including non-steroidal anti-inflammatory drugs (NSAIDS) and physical therapy that resulted in significant clinical improvement.

DQD is a stenosing tenosynovitis of the APL and EPB tendons in the first extensor compartment of the wrist. ${ }^{1}$ Metaplastic changes increase the thickness of the extensor retinaculum of the first compartment and reduce its cross-sectional area causing impingement of the APL and EPB. Instead of an inflammatory aetiology, a degenerative mechanism has been proposed after the observation of myxoid degeneration of the APL and EPB tendon sheaths in biopsies of DQD patients. ${ }^{2}$ Indeed, a case-control study found that a thickened retinaculum was found in all DQD patients and that inflammatory involvement of tendons was an inconstant feature. ${ }^{3}$

Although there are many non-modifiable factors (such as older age, female gender and anatomic variations) that contribute to DQD, modifiable (work-related) factors have not been recognised as risk factors. ${ }^{3}$ Indeed, a systematic review and meta-analysis concluded there was no causal relationship between occupational risk factors and DQD. ${ }^{4}$ Still, it is plausible that work-related activity may aggravate the wrist pain in DQD patients or in those predisposed to develop DQD.

The most common pattern is one or two APLs and one EPB in a single compartment, ${ }^{56}$ but several anatomic variations in the number of tendons and division pattern of this compartment have been described. Indeed, four types were classified by

Learning points

- Ultrasound is a useful imaging technique for diagnosing de Quervain's disease.

- Ultrasound provides important information about anatomic variations within the first extensor compartment.

- Subcompartmentalisation should be detected as it allows proper steroid injection or surgical planning.
Hiranuma et $a l^{7}$ : (type 1) APL and EPB share the same sheath; (type 2) complete septation, APL and EPB have separate tendon sheaths; (type 3 ) incomplete septation, APL and EPB have separate tendon sheaths only in the distal portion and (type 4) EPBlacking type, tendon sheath is normal but lacks EPB.

When subcompartmentalisation is present in patients with DQD, the EPB is frequently more affected than the APL. ${ }^{5}$ The efficacy of steroid injections is dependent on its correct administration within the pathological subcompartment. ${ }^{5}$ Likewise, surgical treatment can be ineffective if the tendon sheath of the pathologic subcompartiment remains unreleased. ${ }^{358}$

This case should arouse awareness regarding subcompartmentalisation of the first extensor compartment of the wrist and how it can influence DQD treatment.

Contributors RPD identified, managed the case and took the lead in writing the manuscript. JJ provided critical feedback and helped shape the analysis and review of the manuscript.

Funding The authors have not declared a specific grant for this research from any funding agency in the public, commercial or not-for-profit sectors.

Competing interests None declared.

\section{Patient consent for publication obtained.}

Provenance and peer review Not commissioned; externally peer reviewed.

\section{ORCID iDs}

Ricardo Pereira Dias http://orcid.org/0000-0001-5905-8416

João Janeiro http://orcid.org/0000-0002-0198-3542

\section{REFERENCES}

1 Moore JS. De Quervain's tenosynovitis. Stenosing tenosynovitis of the first dorsal compartment. J Occup Environ Med 1997;39:990-1002.

2 Clarke MT, Lyall HA, Grant JW, et al. The histopathology of de Quervain's disease. J Hand Surg Br 1998;23:732-4

3 Volpe A, Pavoni M, Marchetta A, et al. Ultrasound differentiation of two types of de Quervain's disease: the role of retinaculum. Ann Rheum Dis 2010;69:938-9.

4 Stahl S, Vida D, Meisner C, et al. Systematic review and meta-analysis on the workrelated cause of de Quervain tenosynovitis: a critical appraisal of its recognition as an occupational disease. Plast Reconstr Surg 2013;132:1479-91.

5 Choi S-J, Ahn JH, Lee Y-J, et al. De Quervain disease: US identification of anatomic variations in the first extensor compartment with an emphasis on subcompartmentalization. Radiology 2011:260:480-6.

6 Motoura H, Shiozaki K, Kawasaki K. Anatomical variations in the tendon sheath of the first compartment. Anat Sci Int 2010;85:145-51.

7 Hiranuma A, Houjo H, Sakaguchi S. De Quervain's tenosynovitis and anatomical variation of firstextensor compartment. Orthop Surg 1972;23:1186-8.

8 Witt J, Pess G, Gelberman RH. Treatment of de Quervain tenosynovitis. A prospective study of the results of injection of steroids and immobilization in a splint. J Bone Joint Surg Am 1991;73:219-22.

Copyright 2021 BMJ Publishing Group. All rights reserved. For permission to reuse any of this content visit

https://www.bmj.com/company/products-services/rights-and-licensing/permissions/

BMJ Case Report Fellows may re-use this article for personal use and teaching without any further permission.

Become a Fellow of BMJ Case Reports today and you can:

- Submit as many cases as you like

- Enjoy fast sympathetic peer review and rapid publication of accepted articles

- Access all the published articles

Re-use any of the published material for personal use and teaching without further permission

Customer Service

If you have any further queries about your subscription, please contact our customer services team on +44 (0) 2071111105 or via email at support@bmj.com.

Visit casereports.bmj.com for more articles like this and to become a Fellow 